\title{
Notas sobre fetichismo, historia e incertidumbre: más allá de la crítica a la austeridad
}

\author{
Notes on Fetishism, History and Uncertainty: \\ Beyond the Critique of Austerity
}

\author{
WERNER BONEFELD \\ University of York
}

\begin{abstract}
Resumen. Estamos en medio de una onda enorme de protestas, rechazos masivos $\mathrm{y}$ multitudinarios de las condiciones contemporáneas. El trabajo se pregunta qué significa decir NO en una sociedad que requiere de los pobres y miserables que subsidien el sistema financiero para mantener la ilusión de una riqueza abstracta. Este subsidio es necesario en la sociedad existente, para asegurar su riqueza y prevenir su implosión. La sociedad capitalista no puede combatirse de una forma directa e inmediata - ¿qué significa realmente luchar contra el dinero, resistir el movimiento de monedas, combatir el movimiento de tipos de interés, luchar contra los movimientos de precios, y resistir a la pobreza en un modo de reproducción social que conlleva la pobreza en su concepto de riqueza? El rechazo a aceptar las cosas tal y como son es enteramente negativo con respecto a las condiciones existentes de reproducción social. Demanda que su progreso continuo se ponga en suspenso.
\end{abstract}

Palabras clave: Adorno, Benjamin, Marx, historia, negatividad, Tiempo-ahora, reproducción social
Abstract. We are in the middle of huge wave of uprisings, of massive, multitudinous refusals to accept the contemporary conditions. The article asks what it means to say NO in a society in which the poor and miserable are required to subsidise the financial system for the sake of sustaining the illusion of abstract wealth. This subsidy is necessary in existing society, to secure its wealth and prevent its implosion. Capitalist society cannot be fought in a direct and immediate manner - what really does it mean to struggle against money, resist the movement of coins, combat the movement of interest rates, fight price movements, and resist poverty in a mode of social reproduction that entails the pauper in its concept of wealth? The refusal to sanction things as they are is entirely negative of the existing conditions of social reproduction. It demands that their further progress comes to a standstill.

Key words: : Adorno, Benjamin, Marx, History, Negativity, Now-Time, Social Reproduction 
"Lo que distingue a estos caballeros [los socialistas franceses] de los defensores de la burguesía es, por un lado, su sensibilidad ante las contradicciones que se encuentran en el sistema y, por otro, la incapacidad utopista para captar la necesaria diferencia entre la forma real y la forma ideal de la sociedad burguesa, que provoca su deseo de emprender la superflua tarea de realizar de nuevo esa expresión ideal, que de hecho no es más que la proyección invertida [Lichtbild] de esa realidad.“

Marx, 1973, pp. 248-49

\section{Prefacio}

Vivimos una época en la que por todas partes se oye hablar de miseria. Los titulares de las noticias han pasado de la guerra y el terror a lo que parece una interminable crisis económica global. En el contexto de la deuda, sin crecimiento económico o como mucho con una tasa de crecimiento lenta, vuelve a estar de moda la acumulación mediante el desposeimiento, toda una generación de trabajadores se ve despedida por reducción de plantilla, y a toda una masa de personas se les han quitado los medios de subsistencia, luchan por sobrevivir; $y$, pese a las apariencias en sentido contrario, la guerra y el terror prosiguen sin descanso. En este contexto, la idea de que el capitalismo produce situaciones deplorables es un punto de vista de lo más optimista. No es lo mismo condiciones deplorables (Zustände) que situaciones deplorables (Mißstände). Las condiciones deplorables dicen que la pobreza es una condición capitalista. Para hacerle frente se requiere un cambio fundamental en las relaciones sociales de producción. Por otro lado, las situaciones deplorables describen circunstancias socioeconómicas totalmente evitables, sean resultado de un desarrollo casual, de incompetencia del gobierno, o de una dura política de clases. Como tales, pueden rectificarse mediante intervenciones políticas bienintencionadas y programas políticos que beneficien a la sociedad en general ${ }^{1}$. En lugar de la ganancia capitalista, las situaciones miserables requieren una solución por medios políticos que considere que la economía es responsable, ante las aspiraciones democráticas, de liberar de la necesidad. Las situaciones deplorables requieren por consiguiente un activismo social que desafíe a tal o cual miseria y a tal o cual ultraje, tratando de aliviar y corregir esto o aquello. ¿Pero qué condiciones sociales son las que constituyen la necesidad de esa pobreza y esa miseria? A fin de cuentas, lo que se necesita es una praxis que combata las condiciones subyacentes de miseria. Adorno (1972) condena, en consecuencia, el activismo por el activismo, y lo rechaza como pseudopraxis que combate esto y aquello pero que deja completamente intactas las condiciones que hacen que exista esto y aquello. De este modo, el "activismo" no sólo es favorecedor deliberado de la sociedad existente, sino que también es regresivo: se engaña creyendo que una situación, por mala que sea, puede rectificarse mediante tal o cual política, mediante tales o cuales medios técnicos. El activismo de situación dada siente el dolor del mundo y ofrece su propio programa como medio de salvación. El activismo contra esto o aquello es engañoso en su concepción de la sociedad. A aquellos cuyos intereses pretendidamente representa, les engaña haciéndoles creer que la solución a su grave situación es en realidad tan sólo cuestión de gobernar adecuadamente. Esencialmente, el activismo 
para tal o cual causa es una publicidad política para algún partido que sea alternativa de gobierno. La protesta contra una miseria realmente existente y que arruina la vida de toda una clase de individuos, la transforma en una baza en la busca de beneficios políticos.

\section{Sobre la sociedad y la naturaleza económica}

El pensamiento crítico no es otra cosa que el ingenio de la razón cuando se enfrenta a una realidad social en la que se exige que los pobres y los miserables subvencionen el sistema financiero para garantizar que se mantenga la ilusión de ficticia riqueza. Sin embargo, tal subvención es del todo necesaria en la sociedad actual, para evitar su implosión. Esta irracionalidad racional de un modo de reproducción social capitalistamente organizado se encuentra en el centro de la crítica de la economía política. Su crítica es subversiva. Pregunta por qué la reproducción social humana adopta esa forma irracional. La subversión se centra en las condiciones humanas y se centra en lo esencial: "el trabajo libre contiene al pobre” (Marx, 1973, p 604.) Y la riqueza capitalista conlleva en su concepción la pobreza del trabajo de los desposeídos. Su atención a lo esencial implica intransigencia ante los actuales modelos y pautas del mundo. Exige que todas las relaciones "en las que el hombre es un ser degradado, esclavizado, abandonado y despreciable deben eliminarse" (Marx, 1975, p. 182). La degradación subsiste en cuanto sociedad inconsciente de sí misma; es decir, una sociedad en la que existe la actividad sensual humana, digamos, en forma de movimiento de monedas que se imponen con una fuerza aparentemente irresistible sobre los suje- tos activos como si el mundo de las monedas fuera un mundo aparte. El fetichismo de los bienes de consumo hace que el mundo humano parezca como un mundo que se rige por leyes naturales, económicas e inmutables. Sin embargo, la naturaleza no tiene nada que ver con él. Lo que se muestra como fuerza objetiva de naturaleza económica es y sigue siendo una fuerza socialmente constituida. La sociedad se rige por abstracciones económicas que se muestran como fuerzas de la naturaleza. La naturaleza económica es una naturaleza constituida socialmente. La sociedad se afirma en forma de una relación entre cosas y por lo tanto existe en y por el movimiento de las cosas socialmente constituidas.

La sociedad es "objetiva" en la medida y "porque" su "propia subjetividad no es transparente". La sociedad es subjetiva "en la medida en que hace referencia a los seres humanos que la componen" (Adorno, 1993a, p. 43). La objetividad "se realiza sólo a través de los individuos". La sociedad como mero objeto incluye el engaño socialmente necesario de que las estructuras y leyes sociales son innatamente naturales. "La tesis de que la sociedad está sometida a las leyes naturales es ideología" (Adorno, 1973, p. 355). La objetividad social no se postula a sí misma; "lo que la constituye es el postulado universal de los sujetos sociales" (1993b, p 127.). Lo que esto significa lo pone bien de manifiesto Marx (1973. p. 239) cuando escribe sobre el dinero fetiche que "una relación social, una relación clara entre personas... se presenta como un metal o una piedra, como algo externo puramente físico que, como tal, se puede encontrar en la naturaleza, y que, en la forma, es indistinguible de su existencia natural". Es decir, la objetividad social "no tiene vida por sí misma" 
(Adorno, 1993, p. 127). Es una objetividad constituida socialmente: las relaciones sociales desaparecen en su apariencia como metal o piedra, y es esta apariencia la que es real. Sólo hay un mundo, y es el mundo de la apariencia. Lo que en la apariencia de la sociedad aparece como "piedra", o "moneda", es sin embargo una relación social clara entre los individuos que subsiste como relación entre "monedas". La sociedad aparece como algo trascendental que gobierna mediante la "mano invisible", que "cuida tanto del mendigo como del rey" (Adorno, 1973, p. 251). Su carácter trascendental es real: el dinero hace que el mundo de vueltas; y sin embargo lo hace únicamente porque, en el capitalismo, los individuos sociales se rigen por el producto de sus propias manos. En resumen, el mundo se manifiesta ciertamente a espaldas de los individuos activos y la sociedad es ciertamente regida por abstracciones reales; sin embargo, es su propio mundo (cf. Marcuse, 1988, p 151).

La crítica que hace Marx del fetichismo equivale por lo tanto a un juicio sobre la existencia. Es decir, la crítica de la economía política equivale a una praxis conceptualizada (begriffenden Praxis) de las relaciones sociales claras en su apariencia como relaciones, por ejemplo, entre monedas (Schmidt, 1974, p. 207). Sostiene que los misterios teóricos encuentran explicación racional en la práctica humana y en la comprensión de esta práctica, y sostiene que esa práctica existe en contra de sí misma en forma de relaciones de objetividad económica. El límite de la cosificación es el hombre cosificado $\mathrm{y}$, ante el hombre cosificado, la crítica del fetichismo es un intento de hacer que la sociedad sea consciente de su propio mundo "monstruoso". En resumidas cuentas, el significado de la objetividad excluye la posibilidad de que ésta también pueda ser sujeto. Sin embargo, ser objeto es parte del significado de la subjetividad. La subjetividad supone la objetivación. En su forma capitalista aparece en la lógica de las cosas. La apariencia [Schein] “es el encantamiento del sujeto en su propio mundo" (Adorno 1969: 159). La circunstancia de que la objetivación [Gegenständlichkeit] exista en forma de relación entre monedas no implica por consiguiente que no haya una lógica todavía sin descubrir, y de hecho imposible de descubrir, que se encuentre únicamente en la cosa misma. Sólo como objeto socialmente determinado puede el objeto ser objeto (véase Adorno 1969: 157). El mundo irracional es un mundo racional.

La obra de Marx se centra en las formas, en un primer momento en las formas de conciencia (es decir, la religión y la ley), y más tarde en las formas de economía política. Este enfoque en las formas comporta una crítica de las relaciones sociales que subsisten en una forma invertida de la sociedad, la que no es regida por los mismos individuos sociales, sino que es regida por el "producto" de sus manos. Es decir, cada "forma" social, incluso la más simple, como por ejemplo la mercancía, "ya es una inversión y hace que las relaciones entre las personas aparezcan como atributos de las cosas“ (Marx, 1972, p. 508) o, más categóricamente, cada forma es una "forma pervertida“" (Marx, 1979, p. 90)². La crítica de las categorías económicas como formas sociales pervertidas subvierte la idea económica de dinero, precio y beneficio al revelar su constitución social. El movimiento de "monedas" no expresa un asunto económico concebido abstractamente. Expresa una relación social definida entre individuos 
que subsiste como relación entre cosas y monedas. En el capitalismo, los individuos están realmente regidos por el movimiento de las monedas; su relación con la sociedad, y con ella su acceso a los medios de subsistencia, la llevan en el bolsillo. Aunque las monedas tienden a la inflación o la depresión, no son sujetos. Sin embargo, abusan de la persona, y también en y a pesar de ella, hasta llegar a la locura y el desastre, desde la conciencia socialmente necesaria de efectivo [cash] y producto, de dinero y ganancia, hasta la pobreza y el hambre, y hasta el derramamiento de sangre y la guerra. El concepto burgués de riqueza es el dinero en el sentido de más dinero, y esta idea de más dinero se objetiva en las personas como simples "agentes de valor" (Adorno, 173, p. 311) que para su vida dependen de la forma en la que se desarrolla la "lógica de lo económico"; el acceso a los medios de subsistencia parece estar regido por el destino, y el destino aparece en forma de crecimiento económico, el cual, si el dinero no se plantea como más dinero deja fuera de los medios de subsistencia a toda una clase de personas. ¿Qué monstruosidad! Una cosa económica, esta moneda, que en su naturaleza no es en realidad más que un pedazo de metal, se manifiesta como un poder del que "pende la vida de todos los hombres" (Adorno, 1973, p. 320). Sin embargo, esta no es una monstruosidad de naturaleza económica, ni de cosas reificadas. Es decir, la idea mitológica de destino se torna no menos mítica cuando se desmitologiza convirtiéndose "en una 'lógica de las cosas' secular" (Ibid., p. 319), o en un sistema-lógica abstracto que estructura los comportamientos económicos a través de las señales de pre- cio, que comprende la libertad de enriquecer y la libertad de hacer pasar hambre. Su naturaleza económica es íntegramente una naturaleza socialmente constituida.

\section{Sobre sociedad y praxis}

Existe, dice Adorno, la necesidad de una "práctica que combata la barbarie", y sin embargo, argumenta con razón, no puede existir dicha práctica (Adorno, 1962, p. 30). La barbarie no puede combatirse de modo directo e inmediato; ¿qué significa realmente luchar contra el dinero, resistirse al movimiento de moneda, combatir contra la ley del valor, y combatir la pobreza en una sociedad que contiene la pobreza en su concepto de riqueza? Una "práctica que combate la barbarie" se refiere a las condiciones sociales previas que hacen posible la barbarie. Para exponer este punto de un modo totalmente distinto: la lucha por la humanización indica por dónde debe ir la lucha contra las relaciones de miseria constituidas; la humanización de las relaciones sociales es el propósito y el fin de la lucha por la emancipación humana con respecto a las relaciones económicas reificadas, con respecto a las relaciones en las que el aumento de riqueza social se manifiesta a la clase ligada al trabajo en forma de lucha constante para acceder a los medios de subsistencia. No obstante, el esfuerzo por humanizar las condiciones inhumanas se ve enfrentado a la paradoja de que presupone que son eternas esas mismas condiciones inhumanas que provocan inicialmente el esfuerzo de humanización. Las condiciones inhumanas no son simplemente un impedimento para la humanización, sino una premisa de su concepto. Entonces, ¿qué significa decir "no"? 
Lo que requiere explicación no es la independencia de las categorías económicas de efectivo y moneda, valor y dinero, como fuerzas más allá de, y también en y a través de, los individuos sociales. Lo que requiere explicación son más bien las relaciones sociales de producción que se manifiestan como relación entre cosas económicas, que se afirman a espaldas de los mismos individuos que componen la sociedad y la sostienen. La idea deAdorno de que el "movimiento total de la sociedad" es "hostil desde el principio" (Adorno, 1970, p. 304) implica por lo tanto más de lo que parece de entrada. No sólo el fetichismo de la mercancía presupone relaciones sociales hostiles, sino que la sociedad existe también en virtud del antagonismo de clases. Es decir, "la sociedad se mantiene viva, no pese a su antagonismo, sino por medio de él"' (Adorno, 1973, 320). La lucha contra el capitalismo, por consiguiente, no es una lucha por la clase obrera. Se mire como se mire, ser miembro de la clase obrera es un gran "infortunio" (Marx, 1983, p. 477). Es decir, la clase no es una categoría positiva. Es un concepto crítico de la falsa sociedad. La crítica de la sociedad de clases no encuentra su solución positiva en trabajadores mejor pagados o condiciones de pleno empleo, etc.; su solución positiva la encuentra tan sólo en la sociedad sin clases, en la que la humanidad se ha liberado de "toda la mugre de siglos y se funda de nuevo" (Marx y Engels 1976: 53); como comuna de "individuos comunistas" (Marcuse, 1958: 127).

En un mundo regido por el movimiento de las monedas, la crítica de la sociedad de clases es íntegramente negativa. La crítica constructiva de la sociedad de clases no equivale a una práctica crítica. Equivale, aducen Horkheimer y Adorno (1972) y Ador- no (1970), a "pensamiento etiqueta". Es un pensamiento "unidimensional". Argumenta en interés del trabajador asalariado con una reivindicación de poder. Es decir, en vez de entender el capital como relación social, considera que el capital es algo económico que, dado el equilibrio de fuerzas de clase, puede hacerse trabajar en beneficio de los trabajadores. El pensamiento etiqueta proclama la "falsedad" (Adorno, 2008a: 28). En vez del "optimismo de la izquierda" que propone un programa de transformación capitalista, que "no habla del diablo, sino que mira el lado bueno" (Adorno 1978: 114), se necesita por consiguiente entender la conceptualidad capitalista de trabajo social.

Las concepciones de clase afirmativas, por bien intencionadas y benévolas que sean sus intenciones, presuponen que la clase obrera es una fuerza productiva que merece un futuro nuevo y mejor. ¿Qué es un salario justo? Marx puntualizó que el " "precio del trabajo' es algo tan irracional como un logaritmo amarillo" (Marx, 1966, p. 818). La demanda de salarios justos y condiciones laborales justas se extrae de las propias condiciones de la "equidad" en el capitalismo, que se basa en el divorcio entre el trabajo social y los medios de subsistencia, y en vez de superar ese divorcio que es el fundamento del capital y el trabajo, promulga que a los trabajadores desposeídos se les pague mejor. Es decir, el divorcio entre el trabajo social y los medios de subsistencia transforma al trabajador en un proletario que es "esclavo de otros individuos que se han hecho dueños de los medios de la existencia humana" (Marx, 1970, p. 13, traducción modificada). ¿Por qué este contenido, es decir, la reproducción social humana, toma la forma de un intercambio equivalente entre los propieta- 
rios de los medios de subsistencia y el desposeído vendedor de la fuerza laboral, y cómo puede ser que se amplíe la riqueza mediante un intercambio entre valores equivalentes? El vendedor de la capacidad de trabajo es fundamentalmente un factor humano del tiempo de trabajo excedente, que es el fundamento de la plusvalía y, por lo tanto del beneficio. La equivalencia de un intercambio entre valores cuantitativamente diferentes tiene que ver, por tanto, con la transformación del trabajo en una actividad laboral productora de plusvalía que acrecienta la riqueza social, permitiendo que el dinero ponga huevos de oro. Incluso en el supuesto de que, en la contratación de mano de obra, se cambie lo equivalente por lo equivalente, esa transacción entre el vendedor y el comprador del trabajo "es tan sólo el viejo truco de todos los conquistadores que compran mercancías de los conquistados con el dinero que les han robado" (1983, p. 456). Es decir, la teoría en pro de la clase obrera afirma la existencia de una clase de personas vinculada a la producción de plusvalía. El capítulo 48 del volumen tercero de El Capital da la crítica que hace Marx de la teoría de clases propuesta por la economía política clásica (y compartida por la ciencia social moderna), de acuerdo con la cual los intereses de clase vienen determinados por las fuentes de ingresos (o, en términos weberianos, la situación del mercado) de los grupos sociales, en vez de estar fundados en las relaciones sociales de producción como sostiene Marx (véase a este respecto Clarke, 1992). La economía política es de hecho una disputa académica sobre cómo puede dividirse y distribuirse entre las clases de componentes de la sociedad el botín sacado del obrero (Marx, 1983, p 559.); y sin duda, cuanto más consiga el obrero, mejor. Al fin y al cabo, es su trabajo social el que produce la "riqueza de las naciones".

Sin embargo, la crítica de la economía política no es la economía política. En contraposición al enfoque de la economía política sobre la distribución de la riqueza, pregunta por la conceptualización de la riqueza social, que es la riqueza en forma de valor, y pregunta cómo es producida esa riqueza, por quién y para qué. Según Marx, la riqueza es producida por el trabajo en aras de una mayor riqueza en forma de valor, y el valor es valor de cambio que se hace visible en forma de dinero. El valor es riqueza como valor valorizado. El tiempo es dinero. La crítica de la economía política equivale, por tanto, a una práctica conceptualizada de la forma capitalista de la riqueza social como basada en la transformación del tiempo de vida de los trabajadores en tiempo de trabajo. No hay tiempo que perder y siempre hay más tiempo que ganar. Eso es, entonces, el "nibbling and cribbling at meal times" o "picotear y mordisquear de la hora de las comidas", porque "los momentos son los elementos de la ganancia" (Marx, 1983, pp., 232, 233). El momento del valor es el tiempo del trabajo socialmente necesario. El trabajo que no se haya llevado a cabo dentro de ese tiempo se ha perdido, no tiene valor, independientemente del tiempo de trabajo que se le ha dedicado, del sudor y las lágrimas de sus esfuerzos productivos, la utilidad de la riqueza material que se ha creado, y de las necesidades que pueda satisfacer. Desde la apropiación de las horas de trabajo no remuneradas hasta la interminable lucha por la división entre horas de trabajo necesario y horas de trabajo excedente, desde la "imposición" de horas de trabajo me- 
diante el robo de tiempo, esas "insignificantes sisas de minutos", esos "tomar unos minutos" (Ibíd., p. 232), hasta el robarle al trabajador átomos de tiempo de trabajo no remunerado adicional mediante una gran flexibilidad de trabajo y "el robo sistemático de lo necesario para la vida del obrero" (Marx, 1983, p. 402), el tiempo de vida del trabajador es tiempo de trabajo. El trabajador aparece entonces como "nada más que tiempo de trabajo personificado" (Marx, 1983, p 233.), un "cadáver de tiempo" (acerca de esto, véase Bonefeld, 2010b).

La idea, entonces, de que el infierno de una sociedad que sufre el flagelo de las clases pueda reformarse en favor de los trabajadores es retrógrada en el sentido de que proyecta una "rebelión conformista" (Horkheimer, 1985) que, por poner un caso, en vez de poner fin a la esclavitud, busca un programa de reformas para mejorar la situación de los esclavos. Aunque "el mundo contiene oportunidades suficientes para el éxito [comunismo]... todo está embrujado" (Adorno y Horkheimer, 2011: 20). Es decir, sólo hay una realidad social, y es la realidad del "encantado y pervertido" mundo del capital (Marx 1966: 830), que se reproduce no a pesar de la lucha de clases, sino más bien en virtud de ella. La actividad humana sensorial subsiste a través del mundo de las cosas económicas, y por lo tanto aparece "como una cosa" (Marx, 1973, p. 157).

\section{En el capitalismo, todo progreso se convierte en una calamidad}

Las relaciones sociales capitalistas han producido una asombrosa expansión de la riqueza social y un extraordinario aumento de la productividad laboral. En el plazo de un minúsculo período histórico de tiempo, ello ha transformado la sociedad humana hasta el punto de hacerla irreconocible. No obstante, pese a tal expansión sin precedentes de la capacidad productiva humana, las horas de trabajo no han disminuido. En el capitalismo, todo progreso social se convierte en calamidad. Cada aumento de la productividad laboral abrevia las horas de trabajo, pero, en su forma capitalista, las alarga. La introducción de maquinaria avanzada hace más ligero el trabajo, pero, en su forma capitalista, aumenta la intensidad del trabajo. Cada aumento de la productividad laboral aumenta la riqueza material de los productores, pero, en su forma capitalista los convierte en pobres. Y lo más importante de todo, una mayor productividad laboral libera mano de obra, hace que se despidan trabajadores. Pero en vez de acortar las horas de trabajo y absorber así en la producción toda la mano de obra sobre la base de una jornada laboral más corta, liberando del "reino de la necesidad" el tiempo de vida, los que tienen trabajo son explotados más intensivamente, mientras que los despedidos se ven en el montón de chatarra de los descartados de un modo de producción que sacrifica “"máquinas humanas' en las pirámides de la acumulación" (Gambino, 2003, p. 104)33.

La riqueza capitalista es riqueza en valor. El valor es categoría de constante expansión, en el dolor de la ruina y por medio de la ruina. El valor es riqueza en forma de expansión incesante de riqueza abstracta en cuanto destrucción. Oculta en el concepto de capital como valor autovalorizado se encuentra la conceptualización del trabajo social. La necesidad de su afirmación en cuanto destrucción -a veces discutida por Marx como dialéctica entre 
fuerzas y relaciones de producción- pertenece a la existencia constituida por el trabajo social en forma de capital.

La destrucción es la pesadilla que constituye el modo capitalista de reproducción social:

Repentinamente la sociedad se encuentra devuelta a un estado de momentánea barbarie; parecería como si una hambruna o una devastadora guerra mundial hubieran cortado los suministros de todo medio de subsistencia; la industria y el comercio parecen destruidos; y ¿por qué? Porque hay demasiada civilización, demasiados medios de subsistencia, demasiada industria, demasiado comercio. Las fuerzas productivas de que dispone la sociedad ya no tienden a fomentar el desarrollo de las condiciones de la propiedad burguesa; al contrario, resultan ya demasiado poderosas para estas condiciones, que las atan, de modo que tan pronto como superan esas ataduras, traen desorden al conjunto de la sociedad burguesa y ponen en peligro la existencia de la propiedad burguesa. Las condiciones de la sociedad burguesa resultan demasiado estrechas para contener las riquezas creadas en su seno. ¿Y cómo supera esta crisis la sociedad burguesa? Por una parte, mediante la destrucción forzosa de una masa de fuerzas productivas; por otra, mediante la conquista de nuevos mercados y mediante una más intensa explotación de los antiguos. (Marx y Engels, 1996: 18-19)

Este comentario del Marx de veintinueve años sobre la globalización no es una anticipación brillante, pues finalmente ha resultado demasiado optimista. Más bien conceptualiza el asunto crítico y, al hacerlo, muestra cuál es su contenido. Lo que se esconde en el concepto de riqueza capitalista son sus necesidades determinadas. Éstas pertenecen al asunto crítico de la sociedad inconsciente de sí misma y constituyen su conceptualidad. La creación en cuanto destrucción es una necesidad válida de las relaciones sociales capitalistas; pertenece a su conceptualidad [Begrifflichkeit]. "La conceptualidad expresa el hecho de que, por mucha culpa que se atribuya a la contribución del sujeto, el mundo concebido no es el suyo, sino un mundo hostil al sujeto" (Adorno 1973: 167). En el mundo de la conceptualidad el hombre desaparece y existe en contra de ella como personificación de categorías económicas -un "sujeto alienado" (véase Backhaus 1992), que constituye el mundo de las cosas y es invisible, perdido y negado en su propio mundo-; la expansión de la riqueza conlleva la desaparición de la riqueza en el sentido de que a toda una clase de personas ligadas al trabajo se la separa de los medios de subsistencia como si el metabolismo social estuviese realmente regido por la idea mítica del destino.

\section{Sólo hay una medida humana que no se puede modificar. Sólo se puede perder (Max Frisch)}

Marx concibe que el comunismo es el movimiento real de la clase obrera (Marx y Engels 1976) y sostiene que la historia es una historia de lucha de clases (Marx y Engels 1996). Este argumento reconoce que la historia ha sido una historia de gobernantes y gobernados, y esa es la única historia que ha habido: una mala-universalidad de transición de un modo de dominación a otro. La universalidad de la historia, sin embargo, es real 
tanto como falsa. En la historia de los vencedores, las víctimas de la historia son invisibles, y es su invisibilidad lo que hace que la historia aparezca como una historia universal que se asemeja a una secuencia de acontecimientos, que deja constancia de los tiempos de gloriosa dominación, de la cual necesariamente se ha borrado el recuerdo de la lucha y la insubordinación. El valor, la astucia, y el sufrimiento de los muertos desaparece por dos veces, una vez en una derrota en la que "ni siquiera los muertos estarán a salvo" de un enemigo que "no ha cesado de triunfar" (Benjamin 1999: 247), y luego otra vez en el presente, que, o bien niega que los muertos hayan existido nunca, o bien ritualiza sus luchas como un acto heroico que culminó en el presente como manifestación incomparable de su valentía (Tischler, 2005). Las luchas del pasado se transforman en un monumento de la historia, erigido para celebrar el actual modo de dominación, para lo cual los muertos hacen las veces de argumento legitimador. Es cierto, dice Benjamin, que "todos los gobernantes son herederos de aquellos que conquistaron antes que ellos". No hay, por tanto "documento de civilización" que no sea "al mismo tiempo un documento de barbarie" (Benjamin 1999: 248). La historia, aunque universal por su aspecto, no es algo automático que se desarrolle en representación de los señores del mundo por la superioridad de su propia lógica victoriosa desarrollada objetivamente. "Quien ha salido victorioso participa hasta hoy en la procesión triunfal, en la que los gobernantes actuales caminan a poca distancia de los que yacen postrados" (Benjamin 1999: 248). No obstante, por universal que pueda parecer el progreso de la historia, el futuro no está escrito todavía, la lucha de clases debe librarse, y sus resultados son inciertos, imprevisibles, y fundamentalmente abiertos, entonces y ahora. Lo que nos aparece como movimiento lineal, fue algo disputado, incierto e imprevisible en su momento. Su progreso hacia el presente parece lógico en su dinámica direccional porque el momento del presente elimina toda duda en su propia veracidad histórica como resultado predeterminado de una secuencia de acontecimientos registrados que fechaba el momento del presente en el pasado.

¿Qué alternativas pudo haber habido en el pasado y cuántas luchas pendieron de un hilo y hubieran podido llevar a un curso de la historia que nos resultaría irreconocible? Ni hay inevitabilidad en la historia, ni la historia es una fuerza irresistible. Está compuesta por los propios sujetos activos y lo que el hombre ha hecho puede cambiarlo el hombre. La historia parece inevitable e irresistible sólo a posteriori, lo cual da a la historia la apariencia de una especie de fuerza objetiva y dinámica direccional, un telos del devenir y de la meta en cuya dirección aparentemente se esfuerza. Para los partidarios de la sociedad actual, la historia ha concluido. Otros dicen que todavía se encamina a algún destino que se supone socialista o comunista, momento en el que concluirá. La historia, sin embargo, no hace la historia. Es decir, i"la historia no hace nada, no "posee grandes riquezas", no "libra batallas"! Es más bien el hombre, el hombre real, vivo, quien hace todo eso, quien posee y lucha; no es la "historia" la que utiliza al hombre [Mensch] como medio para alcanzar sus fines, como si ella fuera una persona aparte. La historia no es más que la actividad del hombre que persigue sus fines" (Marx, 1980: 98). El materialismo histórico no es el dogma indicado tanto por opo- 
nentes hábiles como por partidarios irreflexivos, sino una crítica de las cosas entendidas dogmáticamente. Es decir, la "anatomía humana contiene una clave para la anatomía del simio", pero no a la inversa, la anatomía del simio no explica la anatomía del hombre (Marx 1973: 105). Si la anatomía del simio explicase realmente la anatomía del hombre, entonces el simio tendría ya al hombre como necesidad innata de su evolución; teleología natural o futuro ya escrito ${ }^{4}$. El futuro, sin embargo, no se ha escrito todavía. Tampoco será el resultado de una lógica objetiva abstractamente concebida del desarrollo histórico. La historia no se desarrolla como si fuera una persona aparte. La historia debe ser y será hecha por el hombre en busca de sus fines. Estos fines mismos no están determinados teológicamente, ni tienen fundamento natural, ni están históricamente activos. El propósito del capitalismo es la acumulación rentable de riqueza abstracta. La comunión de propósito humano no es un propósito humano existente. Su realidad es negativa. Es decir, las concepciones lineales de la historia no revelan leyes históricas abstractas. Revelan una acomodación del pensamiento y la práctica a las "condiciones objetivas" existentes. Las concepciones lineales de la historia la conciben como una secuencia continua de progreso del presente hacia su propio futuro.

La izquierda política afirma que la historia está del lado de los oprimidos y que la lucha de los oprimidos, por lo tanto, se mueve a favor de corriente con el avance de la historia. Esta proclamación del progreso hace "afirmaciones dogmáticas" (Benjamin 1999: 252) sobre un futuro de proletarios liberados. ¿Cómo podría uno imaginar un futuro liberado que no sea también un presente futuro?
A la concepción de la historia que concibe la realidad existente como transición hacia el comunismo, Benjamin la califica de "burdel" (Ibíd.: 253) del pensamiento histórico. Critica el capitalismo con una reivindicación de poder, concibe el progreso como algo que depende del éxito político de un partido, se anuncia como la teoría y práctica del progreso de una historia que "sigue su curso... de acuerdo con su propia dialéctica" (Lukács, en Pinkus 1975: 74). En su mejor versión, esta idea de la historia como progreso inminente representa el sentimentalismo de la época, en la peor, cree en sí misma, tratando de imponer una reivindicación dogmática del poder por el poder.

\section{Sobre la crítica del progreso}

La historia no tiene realidad independiente. Se presenta como secuencia de acontecimientos de una batalla a otra, y entre esa división del trabajo y esa otra división del trabajo. Esa apariencia es real, pero, en sí misma, carece de significado. ¿Qué significa realmente decir que la historia es una secuencia de acontecimientos? ¿Acontecimientos de qué clase, y qué es lo que fue tan crucial? Ese aspecto de fuerza que se despliega objetivamente hacia la actual conceptualidad de la riqueza social es engañoso. Crea la idea de la venida de la sociedad de las metas del hombre como un "acontecimiento" del devenir histórico en dirección a la cual se esfuerza por ir la historia. Esta visión de la historia hace que parezca que la sociedad de los libres e iguales se derive de la sociedad existente, degradando la idea misma de la sociedad de las metas del hombre. La dificultad de concebir dicha sociedad independientemente del capitalismo tiene que ver pre- 
cisamente con esa idea. A diferencia de la búsqueda de beneficios, la toma del Estado, la búsqueda y conservación del poder político, del valor económico y de los recursos humanos, sigue una entelequia del desarrollo humano completamente distinta: en ella la riqueza es el tiempo libre, la meta de la humanidad es su propia meta, y en ella la igualdad es una igualdad de necesidades humanas de los individuos. En aras de la emancipación humana, la idea de la historia como fuerza de progreso inexorable debe abandonarse; la idea de progreso va ligada a la sociedad actual, que legitima la existencia de la pobreza como condición de la riqueza futura. La historia aparece como una fuerza trascendente de progreso sólo cuando se la considera por separado, dando lugar a su descripción de una secuencia de acontecimientos históricos, a lo que da nombre el término "historicidad". Es decir, para comprender la historia, se necesita "resquebrajar la secuencia continua de la historia" ${ }^{5}$. Se necesita por lo tanto pensar fuera de la historia, fuera de las batallas, fuera de las luchas de los Levellers y los Diggers, las insurrecciones de esclavos, las revueltas campesinas, las luchas de los Enragés, las huelgas obreras, las revueltas, insurrecciones y revoluciones, incluidas las de San Petersburgo (1917) y Kronstadt (1921), y Barcelona $(1936)^{6}$, para apreciar las tradiciones de los oprimidos, para reconocer el olor del peligro y el hedor de la muerte, para hacerse una idea de la valentía y la astucia de la lucha, captar el espíritu de sacrificio, comprender aunque sea fugazmente la densidad de un periodo en el que la historia casi se detuvo ${ }^{7}$. La historia no conduce a ninguna parte, no tiene telos, ni objetivos, ni meta, y no toma partido. En el peor de los casos, prosigue el camino del progreso victorioso bajo oscuros nubarrones y cielos llenos de humo. Se ha hecho historia. En el mejor de los casos, se detendrá su avance. Esa historia no se ha hecho todavía, aunque se ha intentado a menudo. En nuestro tiempo, a ese intento se lo llama comunismo: ese intento de negación que busca liberar al mundo de "toda la mugre de los siglos".

\section{Lo que es no puede ser}

La verdadera imagen del pasado, dice Benjamin (1999: 247) "pasa como una sombra". ¿Cuándo pasa? ¿Cómo pasa? Pasa "en un momento de peligro", en momentos de lucha valiente cuando el momento presente parece haber llegado a un momento de espera, un momento en el que todo parece posible, y donde todo está en el aire, un tiempo de gran imprevisibilidad e incertidumbre, $y$ por lo tanto un momento en el que la "sangrienta mueca" (Adorno 1975: 43) del progreso alcanza la fuerza real en la experiencia de la lucha. Así, la verdadera imagen del pasado pasa como una sombra en un momento de la mayor incertidumbre, un momento en el que se diluye la certeza del mañana y en el que los monumentos del pasado se resquebrajan para revelar su secreto oculto. Es el momento de la comprensión histórica, en la que la visión a gran escala de una historia gloriosa se transforma pasando de una historicidad de los acontecimientos a una historia con experiencia en la muerte y la destrucción, el saqueo y la expoliación, la esclavitud y el desposeimiento. Ese es entonces el momento de intensa incertidumbre que revela la mueca sangrienta de las luchas pasadas, que hasta ahora se habían ocultado en las formas aparentemente civilizadas de 
gobierno y poder. Ese es entonces el momento en que empiezan a desfilar las víctimas muertas de la historia, para salir del monumento construido por el Estado en su papel de empresario de la memoria (véase Tischler 2005). No hay redención. Sólo la conciencia de que la historia no era lo que parecía, y una repentina comprensión del sacrificio y lucha a muerte anteriores. La experiencia de un tiempo detenido es embriagadora, y llena de peligro. Es esta experiencia la que permite vislumbrar fugazmente el pasado para afianzarse en el presente, revelando una certeza mortífera. Es decir, la redención es un asunto de mantenerse con vida en un momento en el que la certeza del mañana ya no existe: porque "ni siquiera los muertos estarán a salvo" si "el enemigo" vence (Benjamin 1999: 247).

El momento de la emancipación humana es similar a tirar del freno de emergencia en un tren fuera de control, aquí y ahora de modo que el continuo de la historia "se detenga" (Benjamin 1999: 254). Otra forma de expresarlo es decir: el presente futuro es a la vez un presente en transición hacia su propio futuro y un tiempo-ahora que revienta ese continuo de la historia. El momento de tirar del freno de emergencia no es mañana. Es ahora. Comparado con el momento del presente, el tiempo-ahora aparece como mito. El presente es el momento de la aparente certeza y previsibilidad. El tiempo-ahora dice que ahora es el momento de la incertidumbre. Ahora es el momento de detener la marcha adelante del tiempo del reloj, añadiendo unidades de tiempo a unidades de tiempo, haciendo tictac al ritmo de un mundo en el que el tiempo es dinero y el dinero es riqueza. El tiempo-ahora se presenta como un mito porque su acuidad es un momento que no se suma a sí mismo (Bonefeld 2010b). No se mueve hacia adelante en una búsqueda inexorable de riqueza abstracta, acumulando mano de obra viva en las pirámides de la riqueza abstracta, apropiándose de átomos adicionales de tiempo de trabajo no retribuido en beneficio únicamente de la acumulación de riqueza abstracta. En el tiempo-ahora, el tiempo es coraje y astucia. Ahora es el momento de apuntar "a los relojes" para que se detenga su tictac y el tiempo deje de ser dinero y en vez de eso se convierta en tiempo "para el disfrute" (Marx, 1972, p. 252). El tiempo-ahora no es el momento del presente. Es un momento contra el presente, que trata de pararlo en seco. Concebido como momento presente, el tiempo-ahora cesa en cuanto tiempo que lucha contra la barbarie. En vez de ello convierte el "no" del tiempoahora en una "rebelión conformista" a favor de las condiciones existentes, las cuales defiende con doctrinaria creencia en el progreso del presente, de acuerdo con la cual todo irá bien en el futuro, una vez que hayamos pasado la cuenta comunista en el rosario de la historia. ${ }^{8}$

\section{Hacia una conclusión sin promesas}

Sólo una conciencia deificada puede declarar que está en posesión de los conocimientos, la capacidad política y la pericia técnica no sólo para resolver crisis capitalistas, sino, además, para hacerlo en pro de los trabajadores. Su visión del mundo describe la economía capitalista como una práctica irracionalmente organizada del trabajo, y propone el socialismo como práctica racionalmente organizada del trabajo mediante la planificación consciente por parte de la autoridad pública. El anticapitalismo de la plani- 
ficación central de la economía es abstracto en su negación del modo capitalistamente organizado de reproducción social. "La negatividad abstracta" (Adorno, 2008a: 25) ladra a perpetuidad y sin morder. En vez de eso, husmea y encuentra el mundo miserable, desde el exterior por decirlo así, y se presenta como poseedor de la capacidad, la habilidad, la penetración y los medios para resolver la crisis de la economía capitalista "para los trabajadores" (véase Ibid.). La negatividad abstracta describe la teología del anticapitalismo. Teológicamente concebido, el anticapitalismo carece de tiempo-ahora. En lugar de quebrar la secuencia continuada de la historia, promete liberar de la miseria en medio de "un montón de escombros" que "crece hacia el cielo" (Benjamin 1999: 249). La tesis de Benjamin sobre el Ángel de la Historia dice que los pobres y los miserables no serán liberados a menos que se liberen ellos mismos, por su propio esfuerzo, valor y astucia. Herbert Marcuse está pensando en el enigma de este argumento del modo más sucinto cuando sostiene que los trabajadores tienen que estar libres para su liberación de modo que sean capaces de liberarse (Marcuse, 1964). En su opinión, los trabajadores pueden liberarse sólo en la medida en que no sean trabajadores, sobre la base de su ausencia de identidad. El argumento de Marcuse es pertinente: para detener el avance del capitalismo se requiere una identidad no-capitalista, y la dificultad de su idea es simple: tal identidad no pertenece al presente, que es un presente capitalista. ¿Qué significa realmente decir "no" a un modo capitalistamente organizado de subsistencia humana? Decir "no" al capitalismo es simple. Pero decir qué es el "no", eso es di- fícil. Por lo pronto, el "no" no es externo a la misma sociedad a la que se opone, sino que opera dentro de ella. Como ocurre con la llamada de Marx a la lucha de clases como motor de la historia, el "no" conduce hacia adelante el mundo negativo. Es su fuerza dinámica. Es más, decir qué es el "no" compromete al "no" en la medida en que pasa a ser positivo en su afirmativo "sí" a algo que no tiene contenido válido salvo la sociedad misma a la que se opone. El "no" es inmanente a la sociedad burguesa y le confiere su dinámica.

Se precisa, pues, una concepción realista de la lucha por la sociedad de las metas del hombre. Hay que redescubrir la lucha de clases como laboratorio de emancipación humana. Esta lucha no sigue no se sabe qué idea abstracta. Es una lucha por el acceso a "las cosas toscas y materiales sin las cuales no podrían existir cosas refinadas y espirituales" (Benjamin 1999: 246). ¿Qué es entonces aquello por lo que está luchando la clase obrera "en sí"? "En sí", la clase obrera lucha por mejores salarios y condiciones, y defiende los niveles y condiciones salariales. Lucha contra el "hambre de lobo que el capital tiene de mano de obra excedente" y su destructiva conquista de átomos adicionales de tiempo de trabajo, y por ende contra su reducción a un mero cadáver de tiempo. Lucha contra una vida constituida únicamente por horas de trabajo y por lo tanto contra que su vida humana se vea reducida a un mero recurso económico. Lucha por el respeto, la educación y el reconocimiento de la significación humana, y sobre todo lucha por alimento, vivienda, ropa, cariño, amor, afecto, conocimiento y dignidad. Lucha contra que su tiempo de vida se reduzca a tiempo de tra- 
bajo, contra que su humanidad se reduzca a un recurso económico, contra que su existencia vital se reduzca a la personificación de un horario laboral. Su lucha como clase "en sí misma" es en realidad una lucha "por ella misma": por vivir, por la distinción humana, por la duración de su vida, y sobre todo, por la satisfacción de las necesidades humanas básicas. Todo ello lo hace en condiciones (Zustände) en las que el aumento de la riqueza material que ha producido hace retroceder los límites de la forma capitalista de riqueza. Cada pretendido efecto trickle-down que la acumulación capitalista podría generar presupone un previo y sostenido trickle-up en la acumulación capitalista de riqueza. Y entonces la sociedad "se encuentra de repente devuelta a un estado de momentánea barbarie; parecería como si la hambruna, una guerra mundial devastadora, la hubiesen privado de todo medio de subsistencia" (Marx y Engels, 1996: 18-19). Para Benjamin y Marx, la experiencia de carecer de todo medio de subsistencia convierte a la clase oprimida en depositaria del conocimiento histórico. Es la lucha de clases la que "proporciona una experiencia única con el pasado", y la comprensión del presente (Benjamin 1999: 254). El que esta experiencia "se concrete en cambiar las formas de represión como la resistencia a la represión" (Adorno 1973: 265) o se concrete en formas de represión es cuestión de la historia experimentada. Entendido críticamente, y en contraposición con la tradición clásica, el materialismo histórico no es sólo una crítica de las cosas entendidas dogmáticamente. Es decir, en su versión más depurada, piensa en contra del flujo de la historia y, como tal, realmente "cepilla la historia a contrapelo" (Benjamin 1999: 248), de modo que la razón crucial de la emancipación humana no se convierta en "una más de las ideas políticas de las que se suponía que tenía que sacarnos" (Adorno 1973: 143).

La existencia de mano de obra humana como factor económico de producción no implica la reducción de la conciencia a la conciencia económica. Implica el concepto de economía como concepto experimentado, y conciencia económica como conciencia experimentada. Como mínimo, la conciencia económica es una conciencia infeliz. Es esta conciencia la que exige reconciliación. En suma, "la libertad es vana ilusión mientras una clase de humanos pueda matar de hambre a otra con total impunidad. La igualdad es vana ilusión mientras los ricos ejerzan el derecho a decidir sobre la vida y la muerte de los demás" (Roux 1985: 147).

\section{Posdata}

¿Dónde está lo positivo? La sociedad de las metas del hombre únicamente se puede definir negando. La historia no promete nada. La historia no hace nada. La hacen. En la lucha contra un mundo negativo no hay nada seguro, excepto la miseria misma. Sin embargo, también la incertidumbre es un concepto de lucha experimentado (Bonefeld 2004). Históricamente ha tomado la forma del "consejo", la Comuna, la Raete, las asambleas: esa democracia de la calle que, pese a las apariencias en sentido contrario, no manifiesta ningún impasse. Es el laboratorio de la sociedad de los libres e iguales: su validez es su propia incertidumbre. 


\section{REFERENCIAS BIBLIOGRÁFICAS}

Adorno, T. (1962) Einleitung zur Musiksoziologie, Suhrkamp, Frankfurt.

Adorno, TW. (1969) 'Marginalien zu Theorie und Praxis', in Stichworte Kritische Modelle 2, Suhrkamp, Frankfurt.

Adorno, TW. (1970), Ästhetische Theorie, Suhrkamp, Frankfurt.

Adorno, TW. (1972), Soziologische Schriften I, in Gesammelte Werke, vol. 8, Suhrkamp, Frankfurt.

Adorno, TW. (1973) Negative Dialectics, Routledge, London.

Adorno, TW. (1975) Gesellschaftstheorie und Kulturkritik, Suhrkamp, Frankfurt.

Adorno, TW. (1978) Minima Moralia: Reflections from Damaged Life, Verso, London.

Adorno, T. (1993a), 'Einleitung', Der Positivismusstreit in der deutschen Soziologie, dtv, Munich.

Adorno, T. (1993b), 'Zur Logik der Sozialwissenschaften', in Der Positivismusstreit in der deutschen Soziologie, dtv, Munich.

Adorno, TW. (2008a) Lectures on History and Freedom, Polity, Cambridge.

Adorno, TW. (2008b) Lectures on Negative Dialectics, Polity, Cambridge.

Adorno, TW. and M. Horkheimer (2011) Towards a New Manifesto, Verso, London.

Backhaus, H.G. (1992), 'Between Philosophy and Science: Marxian Social Economy as Critical Theory', in Bonefeld, W. R. Gunn and K. Psychopedis (eds.) Open Marxism, vol. I, Pluto, London.

Benjamin, W. (1999) Illuminations, Pimlico, London.

Bonefeld, W. (2000) 'Die Betroffenheit und die Vernunft der Kritik', in Bruhn J, M
Dahlmann, and C Nachmann (eds) Kritik der Politik, Ca Ira, Freiburg.

Bonefeld, W. (2004) 'Uncertainty and Social Autonomy', The Commoner no 8, Winter 2004, pp. 1-6.

Bonefeld, W. (2010a) 'History and Human Emancipation', Critique, 38/1, pp. 61-73.

Bonefeld, W. (2010b) 'Abstract Labour: Against its Nature and on its Time', Capital \& Class, vol. 34/2, pp. 257-276.

Bonefeld, W. (2012), Negative Dialectics in Miserable Times: Notes on Adorno and Social Praxis', in Journal of Classical Sociology 12 (1), pp. 122-34.

Brendel, C. (2002) 'Kronstadt: Proletarian Spin-Off of the Russian Revolution', in Bonefeld W. and S. Tischler (eds) What is to be Done?, Aldershot: Ashgate.

Clarke, S. (1992) Marx, Marginalism and Modern Sociology, 2nd ed., Palgrave, London.

Gambino, F. (2003), 'A Critique of the Fordism of the Regulation School', in W. Bonefeld (ed.), Revolutionary Writing, Autonomedia, New York, 2003.

Holloway, J. (2010), Crack Capitalism, Pluto, London.

Horkheimer, M. (1985) The Eclipse of Reason, Continuum, New York.

Horkheimer, M. and TW. Adorno (1972) Dialectics of Enlightenment, Verso, London.

Marcuse H (1958) Soviet Marxism: A Critical Analysis, Roudledge \& Kegan Paul, London.

Marcuse, H. (1964) One Dimensional Man, Roudledge \& Kegan Paul, London.

Marcuse, H. (1988), 'Philosophy and Critical Theory', in ibid. Negations, Free Association Press, London. 
Marx, K. (1970) Critique of the Gotha Programme, in Marx/Engels Selected Works, vol. 3, Progress Publishers, Moscow.

Marx, K. (1972) Theorien des Mehrwerts, MEW 26.3, Dietz, Berlin.

Marx, K. (1973), Grundrisse, Penguin, London.

Marx, K. (1975), Contribution to the Critique of Hegel's 'Philosophy of Right'. Introduction, in Collected Works, vol. 3, Lawrence \& Wishart, London.

Marx, K. (1966), Capital, vol. III, Lawrence \& Wishart, London.

Marx, K. (1979), Das Kapital, MEW 23, Dietz, Berlin.

Marx, K. (1980), Die heilige Familie, in MEW 2, Dietz, Berlin.

Marx, K. (1983) Capital, vol. I, Lawrence \& Wishart, London.

Marx, K. and F. Engels (1996) The Communist Manifesto, Pluto, London.
Marx, K. and F. Engels (1976) The German Ideology, in Collected Works, vol 5, International Publishers, New York.

Pinkus, T. (ed.) (1975) Conversations with Lukacs, MIT Press, Cambridge, MA.

Roux, J. (1985) 'Das "Manifest der Enragés", in ibid, Freiheit wird die Welt erobern, Reden und Schriften, Röderberg, Frankfurt.

Schmidt, A. (1974), 'Praxis', Gesellschaft: Beiträge zur Marxschen Theorie 2, Suhrkamp, Frankfurt.

Schmidt, A. (1983) History and Structure, MIT Press, Cambridge MA.

Tischler, S. (2005) 'Time of Reification and Time of Insubordination. Some Notes' in Bonefeld, W. and K. Psychopedis (eds) Human Dignity, Ashgate, Aldershot.

\section{NOTAS}

${ }^{1}$ Sobre la distinción entre situaciones deplorables y condiciones deplorables, véase Bonefeld (2000).

${ }^{2}$ Adaptado del alemán original, que usa la frase "verrueckte Form ". En alemán verrueckt tiene doble significado: hombre y desplazado. Lo traduzco como "pervertido".

${ }^{3}$ La calamidad social del desarrollo capitalista se ha tomado de Karl Marx (1983: 416).

${ }^{4}$ Sobre esto, ver Schmidt (1983) y Bonefeld (2010a).

${ }^{5}$ Uso esta frase en referencia a la teoría negativa del capitalismo efectuada por Holloway (2010).

${ }^{6}$ Sobre la conexión entre San Petersburgo y Kronstadt, véase Brendel (2002).

${ }^{7}$ La idea de pensar fuera de la historia y en vez de sobre la historia deriva de la dialéctica negativa de Adorno (1973), que sostiene que para pensar con miras a descifrar la sociedad capitalista tiene que pensar fuera de la sociedad. Para él, pensar sobre la sociedad, o sobre la historia, equivale a un argumento basado en juicios hipotéticos que considera el mundo un "como si", dejando intacta la realidad misma y conduciendo a afirmaciones dogmáticas sobre su carácter. La teoría crítica, al menos esa es su intención crítica, descifra la sociedad desde dentro, buscando su disolución como continuo de inevitables e irresistibles fuerzas sociales, acontecimientos políticos, leyes económicas (de escasez), y datos empíricos. Sobre esto, véase Bonefel (2012).

${ }^{8} \mathrm{El}$ "rosario que pasan nuestras manos" se refiere a la crítica que hace Benjamin de un materialismo histórico que ha caído en el método teórico del historicismo, que concibe la historia como secuencia de acontecimientos. 